\title{
Is Catheter Angiography Still Necessary for the Follow-Up of Spinal Malformations after Treatment?
}

W e read the recently published paper by Mathur et $\mathrm{al}^{1}$ regarding the most appropriate technique to follow-up patients treated for spinal malformations, particularly dural fistula, and they propose to do this by MRA.

In our hospital, we follow-up these pathologies by MRA, and conventional angiography is performed only when there is a radioclinical discrepancy.

We understand the paper has limitations due to being a retrospective study; however, we have the following remarks:

- We believe the use of high field significantly improves the quality of MRA, particularly because of the size of the vessels. ${ }^{2,3}$

- The use of contrast medium with vascular remnant ${ }^{4}$ or a doubly concentrated contrast medium for dynamic sequences also improves the identification of lesions and allows better analysis of these lesions.

- Performing MIP and MPR reconstructions improves the accuracy of diagnosis.

Finally, we think that it is important to standardize the follow-up of these pathologies, as far as the type and quantity of contrast medium and type of field used. Although these pathologies are

http://dx.doi.org/10.3174/ajnr.A5087 not frequent, most of them are curable, and they can cause considerable deficits with tremendous impact on the daily life of patients if not treated.

Disclosures: Zsolt Kulcsar-UNRELATED: Consultancy: Stryker Neurovascular, Balt.

\section{REFERENCES}

1. Mathur S, Symons SP, Huynh TJ, et al. First-pass contrast-enhanced MR angiography in evaluation of treated spinal arteriovenous fistulas: is catheter angiography necessary? AJNR Am J Neuroradiol 2017;1:200-05 CrossRef Medline

2. Vargas MI, Barnaure I, Gariani J, et al. Vascular imaging techniques of the spinal cord. Semin Ultrasound CT MR 2016 July 12. [Epub ahead of print] CrossRef

3. Vargas MI, Gariani J, Sztajzel R, et al. Spinal cord ischemia: practical imaging tips, pearls, and pitfalls. AJNR Am J Neuroradiol 2015;36: 825-30 CrossRef Medline

4. Vargas MI, Nguyen D, Viallon M, et al. Dynamic MR angiography (MRA) of spinal vascular diseases at 3T. Eur Radiol 2010;20:2491-95 CrossRef Medline

(D) M.I. Vargas

(D). Boto

(iD) Zulcsar

Division of Neuroradiology DISIM, Geneva University Hospital Geneva, Switzerland 